\title{
Incidência de Leifsonia xyli subsp. xyli em áreas de multiplicação de cana-de-açúcar no Espírito Santo, sul da Bahia e oeste de Minas Gerais
}

\author{
Elaine Cristina de Ponte ${ }^{1}$, Silvaldo Felipe da Silveira ${ }^{1}$, Josil de Barros Carneiro $\mathrm{Jr}^{2}$ \& Rozana Moreira Pereira de \\ Lima $^{1}$
}

${ }^{1}$ Laboratório de Entomologia e Fitopatologia, Universidade Estadual do Norte Fluminense Darcy Ribeiro, CEP 28013-600, Campos dos GoytacazesRJ; ${ }^{2}$ Laboratório de Fitopatologia, Campus Dr. Leonel Miranda, Universidade Federal Rural do Rio de Janeiro, Cep 28.000-138, Campos dos Goytacazes-RJ.

Autor para correspondência: Silvaldo Felipe da Silveira (silvaldo@ uenf.br)

Data de chegada: 25/05/2006. Aceito para publicação em: 20/11/2010.

\section{RESUMO}

1371

Ponte, E. C.; Silveira, S. F.; Carneiro, J. B.; Lima, R.M.P.. Incidência de Leifsonia xyli subsp. xyli em áreas de multiplicação de cana-de-açúcar no Espírito Santo, Sul da Bahia e Oeste de Minas Gerais. Summa Phytopathologica, v.36, n.4, p.313-321, 2010.

O controle do raquitismo-da-soqueira da cana-de-açucar, causado pela bactéria Leifsonia xyli subsp. xyli $(L x x)$, requer o diagnóstico preciso da doença, pela detecção do patógeno na seiva do xilema. Neste trabalho, avaliou-se a incidência do raquitismo em 108 talhões (principalmente de primeiro e segundo cortes) distribuídos em 7 municípios do Espírito Santo, sul da Bahia e oeste de Minas Gerais, nos anos de 2003 e 2004, totalizando 558 ha amostrados. Para detecção do patógeno empregou-se a técnica sorológica Dot BlotEIA (Dot Blot Enzyme Imunoassay). O raquitismo foi diagnosticado em 67,6\% dos talhões amostrados (67,7\% da área). Em 2003, a incidência média de colmos infectados (IC\%) correlacionou-se positivamente com a idade de corte $(4,8 \%$ nas áreas de primeiro corte e $10,3 \%$ nas áreas de sexto corte). No ano de 2004, observou-se elevada incidência de raquitismo em cana de primeiro corte $(\mathrm{IC}=18 \%)$. A doença foi diagnosticada em 28 dentre 34 variedades estudadas. Nestas, a incidência varietal média variou entre 0,6 e $42 \%$, em áreas predominantemente de primeiro e segundo corte, atingindo IC máxima de $59,5 \%$ em talhão de canaplanta da variedade RB855113. As variedades RB72454, SP711406 e SP813250, que tiveram número razoável de talhões amostrados, apresentaram geralmente valores de IC (por talhão) menores que $10 \%$. Conclui-se que o raquitismo-da-soqueira encontra-se amplamente disseminado nas regiões estudadas e que as mudas utilizadas para a renovação dos canaviais possuem altos índices de contaminação por Lxx. Estudos adicionais devem ser conduzidos para se caracterizar variedades regionais promissoras quanto à resistência/tolerância ao raquitismo, visando-se aperfeiçoar o manejo varietal e melhorar a sanidade das mudas.

Palavras-chave adicionais: Sacharum sp., Sorologia, raquitismo-da-soqueira, sanidade de mudas.

\begin{tabular}{|c|c|}
\hline \multicolumn{2}{|c|}{ ABSTRACT } \\
\hline \\
\hline $\begin{array}{l}\text { This paper describes a survey of the Ratoon Stunting Disease } \\
\text { (RSD) prevalence in } 108 \text { sugarcane multiplication areas ( } 558 \text { ha) of } \\
\text { seven municipalities of the Espírito Santo, western of Minas Gerais } \\
\text { and southern Bahia States, during } 2003 \text { and } 2004 \text {. The diagnostic } \\
\text { method of RSD is mainly based on detection of the pathogenic } \\
\text { bacterium Leifsonia xyli subsp. xyli ( } L x x \text { ) in xylem sap extracts, which } \\
\text { is important on sugarcane propagation material to direct the control } \\
\text { of disease. The Dot Blot Enzyme Immunoassay (Dot Blot-EIA) was } \\
\text { used as diagnostic method of RSD on this work. The pathogen was } \\
\text { detected in } 67.6 \% \text { of the sampled areas ( } 67,7 \% \text { of the whole area). In } \\
2003 \text {, the average incidence of infected stalks (canes) was correlated } \\
\text { with the crop age, being } 4.8 \% \text { for first harvested (one year) areas and }\end{array}$ & $\begin{array}{l}\text { IC ( } 18 \% \text { ) was observed for one year areas. Twenty eight cultivars } \\
\text { were infected by } L x x \text { of a total of } 34 \text { sampled. The IC varied from } 0.6 \\
\text { to } 42 \% \text { for infected cultivars. The highest IC of } 59,5 \% \text { was observed } \\
\text { for RB } 855113 \text { in an one year area. All the uninfected cultivars were } \\
\text { poorly sampled (one area per cultivar only). Despite cultivars } \\
\text { RB } 72454 \text {, SP711406 and SP } 813250 \text { were susceptible to RSD they } \\
\text { presented IC values lowers than } 10 \% \text { in general, being considerate } \\
\text { intermediate resistant to RSD. We concluded that RSD was found } \\
\text { largely disseminated in the studied regions and the propagations } \\
\text { materials used for replanting were highly contaminated by } L x x \text {. } \\
\text { Additional studies have to be taken to characterize the cultivar } \\
\text { resistance or tolerance to RSD and to improve the cultivar manage } \\
\text { and the sanity of the seedcane nurseries in the studied regions. }\end{array}$ \\
\hline
\end{tabular}

Keywords: Sacharum, Serology, Ratoon Stunting Disease, seedcane sanity. 
O raquitismo-da-soqueira da cana-de-açúcar (em inglês Ratoon Stunting Disease - RSD) é causado pela bactéria Leifsonia xyli subsp. $x y l i-\operatorname{Lxx}(11,12)$. Esta doença foi pela primeira vez constatada no Brasil, em Campos dos Goytacazes (RJ), em 1956 (24). Na região nordeste do Brasil, avaliações de cultivares de cana em relação ao raquitismo-da-soqueira indicam reduções de produtividade entre $10 \mathrm{e}$ $25 \%$. Nas variedades SP 791011 e RB 72454, que ainda são muito plantadas atualmente, a redução foi de 15,9 e $11,4 \%$, respectivamente (5).

Uma das limitações das pesquisas com raquitismo-da-soqueira da cana-de-açucar é a necessidade de método de diagnóstico da doença, uma vez que seus sintomas são inespecíficos, os quais podem ser evidenciados em algumas variedades suscetíveis somente em épocas com déficit hídrico (23). Pelo fato da doença não apresentar sintomas aparentes, os produtores não percebem a necessidade de controle do raquitismo (22). O diagnóstico do raquitismo requer a detecção da bactéria causadora da doença em amostras de seiva do xilema, extraídas de internódios basais de colmos amostrados no campo, utilizando-se para isso técnicas sorológicas $(2,3,13,15,17)$ ou análise de PCR (19). A técnica sorológica de Dot Blot EIA (Dot Blot Enzyme Immunoassay ou simplesmente Dot Blot) embora seja menos sensível que a baseada na amplificação do DNA, é, ainda, largamente empregada, pois o soro bruto é bastante específico contra $\operatorname{Lxx}$ (3), sendo uma técnica relativamente barata e adequada para levantamentos de campo, onde se busca detectar níveis mais elevados de colonização dos colmos, com acima de $2.10^{6}$ u.f.c. $/ \mathrm{mL}(3,17)$.

Acredita-se que em regiões produtoras do Brasil, como no Nordeste, no litoral norte-fluminense e norte-capixaba, o raquitismoda-soqueira seja doença importante, pois os sintomas agravam-se com o déficit hídrico, o que não é raro ocorrer na cultura da cana nestas regiões. Estudos de variedades de cana-de-açucar resistentes ou tolerantes a doenças são escassos, especialmente nas regiões mencionadas acima (5). Ademais, variedades modernas, descritas como resistentes ao RSD em sua região de origem, podem se mostrarem suscetíveis em outras regiões, onde o estresse hídrico é pronunciado (18). O levantamento da incidência do RSD em áreas de multiplicação pelo uso de técnicas sorológicas pode indicar quais as variedades mais infectadas (suscetíveis) bem como direcionar medidas de controle, tais como: não utilização de mudas com altos índices de contaminação; limpeza clonal de variedades elites suscetíveis e intolerantes ao raquitismo; reforma de canaviais altamente contaminados com variedades resistentes ou tolerantes ao raquitismo; desinfestação de instrumentos de corte em áreas de multiplicação e viveiros; escolha de talhões e áreas de multiplicação livres de doenças ou com baixo índice de contaminação $(4,8,15)$.

Neste trabalho, efetuou-se um levantamento da incidência de colmos infectados por $L x x$ em áreas de multiplicação clonal de quatro destilarias das regiões Norte Capixaba, Sul da Bahia e Oeste Mineiro, nos anos de 2003 e 2004. Objetivou-se, com isso, estabelecer um panorama geral da sanidade das mudas utilizadas nas regiões, quanto aos níveis de contaminação por $L x x$.

\section{MATERIAL E MÉTODOS}

No ano de 2003, foram amostrados 64 talhões em áreas de multiplicação, totalizando 324 ha amostrados, onde foram coletadas aproximadamente 4.000 amostras de colmos ou touceiras ( 1 colmo/ touceira). Em 2004, foram amostrados outros 44 talhões de áreas de multiplicação, totalizando cerca de 2000 amostras (colmos) correspondentes a 234 ha. As amostragens foram direcionadas para talhões de cortes iniciais e em idade superior a 9 meses (Tabelas 1 e 2). De talhões com área inferior a cinco ha retiraram-se 45 amostras de colmo (ou touceiras) e de talhões com áreas superiores a cinco ha retiraram-se 90 amostras. Na coleta de amostras os amostradores entravam nas linhas de cana espaçadas de 5 em 5 ou de 10 em 10 linhas, conforme a largura do talhão. Ao entrar nas linhas, dependendo do comprimento destas, ou conforme o comprimento do talhão, os amostradores percorriam uma distância de 50 a 100 m e retornavam coletando, a cada $10 \mathrm{~m}$, um dos colmos mais velhos da touceira, quebrando-o rente ao solo. Os colmos foram retirados para o carreador onde foram despalhados, limpos e cortados na altura do quarto internódio basal, identificados e amarrados em feixes, para transporte até o laboratório.

A extração da seiva do xilema foi feita por centrifugação de amostras da região central dos colmos retiradas dos segundo ou terceiro internódios basais (2). Para isso, da região central de cada internódio basal foi retirada uma amostra cilíndrica de um centímetro de diâmetro e de até $10 \mathrm{~cm}$ de comprimento, com auxílio de furador de rolhas. As amostras (cilindros centrais dos internódios basais) foram novamente fracionados com $1 \mathrm{~cm}$ de comprimento e acondicionados em tubos de microcentrífuga de $1,5 \mathrm{ml}$. Procedeu-se a centrifugação por $2 \mathrm{~min}$, a 8.000 g (13.000 rpm na microcentrífuga FANEM $^{\circledR}$ - mod. 243) e o extrato resultante foi congelado e mantido a $-20^{\circ} \mathrm{C}(2)$.

Para detecção do patógeno foi utilizada a técnica sorológica de Dot Blot EIA ("Dot Blot Enzyme Immunoassay", Harisson \& Davis (16) modificada conforme Carneiro et al. (3), sendo utilizada para revelação (coloração) da membrana a enzima fosfatase alcalina. Utilizou-se anticorpo policlonal específico contra Leifsonia xyli subsp. xyli produzido no Laboratório de Entomologia e Fitopatologia da UENF (3). Os extratos das amostras, após descongelarem a temperatura ambiente, foram fixados em membrana de nitrocelulose (poros de 0,2 $\mu \mathrm{m})$ sob vácuo. Cada membrana recebeu um total de 88 amostras, sendo que quatro referiam-se aos padrões (controles positivos e negativos) e o restante às amostras dos talhões. Os padrões consistiram de: (i) suspensão de $10^{6}$ células bacterianas obtidas de cultura pura de $L x x$, (ii) seiva de cana doente cuja presença da bactéria fora previamente confirmada em ensaio sorológico, (iii) seiva de cana doente diluída 10 vezes em água destilada e (iv) seiva de cana sadia pré-filtrada em milipore $(2 \mu \mathrm{m})(3)$. O ensaio sorológico iniciou-se com a hidratação da membrana de nitrocelulose $\left(\right.$ Sigma $\left.^{\circledR}\right)$ em água super pura, por 10 min. Sob vácuo, foi aplicada na membrana $10 \mu 1$ de cada amostra. Em seguida: bloqueou-se a membrana por $60 \mathrm{~min}$ em solução tampão TS (Tris $100 \mathrm{mM}, \mathrm{NaCl} 1,5 \mathrm{M}$, Tween-20 0,5\% pH 7,4) com 0,3\% de leite desnatado em pó (Molico ${ }^{\circledR}$ ); lavou-se em solução TS, por três vezes, durante $10 \mathrm{~min}$ cada; incubou-se $60 \mathrm{~min}$ em solução do antissoro diluído (1: 20.000 em tampão TS com 0,1\% de leite); lavou-se em tampão TS, por três vezes, durante 10 min cada; incubou-se novamente a membrana por 120 min em solução do anticorpo de cabra contra IgG de coelho, conjugado a fosfatase-alcalina (Sigma Chemical Co. ${ }^{\circledR}$ ), diluído 1: 2.000 em solução salina tampão TS com $0,1 \%$ de leite em pó; lavouse por três vezes em solução TS e por 10 minutos em solução tampão fosfato $1 \mathrm{M}$. O processo sorológico foi finalizado incubando-se (sob agitação a $60 \mathrm{rpm}$ e no escuro) a membrana por $15 \mathrm{~min}$ em solução reveladora (Napthol-as-phosphate 0,3g, N, N Dimethyl formamide $5 \mathrm{ml}$, Tris-base $24 \mathrm{~g}$, Fast blue 0,1g, pH 9,1). Após incubação, a membrana foi lavada por 30 min em solução de hipoclorito de sódio $2 \%(\mathrm{v} / \mathrm{v})$ para remoção de manchas residuais. Todo o processo sorológico foi conduzido sob agitação $60 \mathrm{rpm}$, a temperatura ambiente.

A detecção positiva de $L x x$ nos extratos foi evidenciada pelo 
Tabela 1. Resultados do levantamento da incidência de colmos de cana-de-açucar soro-positivos para a presença de Leifsonia xyli subsp. xyli, agente causal do raquitismo da soqueira, no ano de 2003, em variedades plantadas em áreas de multiplicação das regiões canavieiras do norte capixaba, oeste mineiro e sul da Bahia. Detecção feita pela técnica sorológica de Dot Blot-EIA (Carneiro et al., 2004).

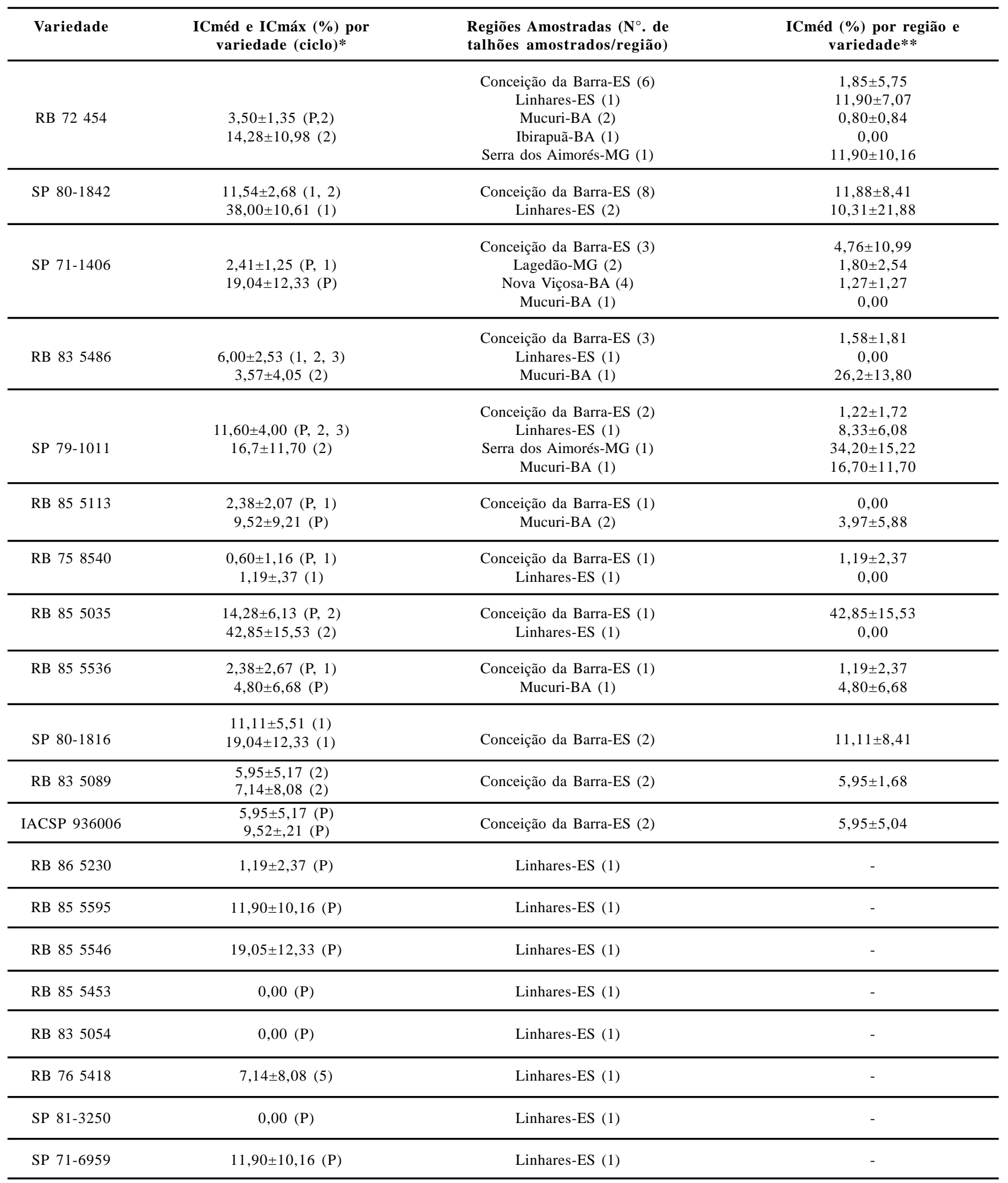

* média e intervalo de confiança dos valores de IC $(\%)$ dos talhões amostrados e incidência máxima de talhão, em cana-planta até o sexto corte [ciclo = cana-planta $(\mathrm{P})$ e do $1^{\mathrm{a}}$ a $5^{\mathrm{a}}$ cana-soca (de 1 a 5, respectivamente)], por variedade. ** média e intervalo de confiança da incidência de colmos infectados (IC\%) dos talhões amostrados por região. 
Tabela 2. Resultados do levantamento da incidência de colmos de cana-de-açucar soro-positivos para a presença de Leifsonia xyli subsp. xyli, agente causal do raquitismo da soqueira, no ano de 2004, em variedades plantadas em áreas de multiplicação das regiões canavieiras do norte capixaba, noroeste mineiro e sul da Bahia. Detecção do patógeno feita pela técnica sorológica Dot Blot-EIA (Carneiro et al., 2004).

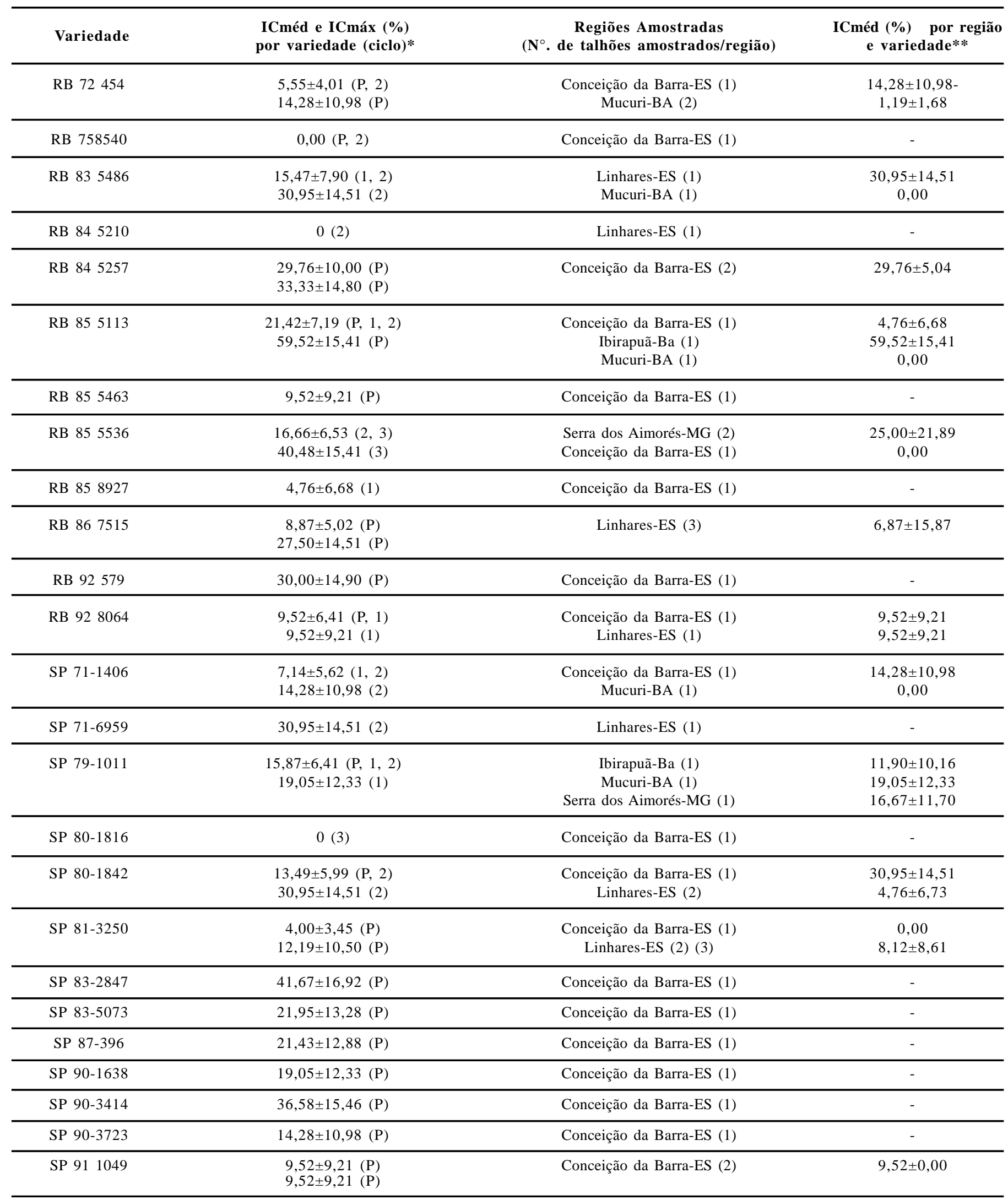

* média e intervalo de confiança dos valores de IC $(\%)$ dos talhões amostrados e incidência máxima de talhão, em cana-planta até o sexto corte $\left[\right.$ ciclo $=$ cana-planta $(\mathrm{P})$ e do $1^{\text {a }}$ a $5^{\mathrm{a}}$ cana-soca (de 1 a 5, respectivamente)], por variedade. ** média e intervalo de confiança da incidência de colmos infectados (IC\%) dos talhões amostrados por região. 
aparecimento de coloração azul, mesmo que tênue, na posição correspondente à da aplicação das respectivas amostras, em comparação às das amostras-controle.

A incidência de colmos contaminados (IC \%) foi calculada pela contagem do número de reações soro-positivas em relação ao número total de amostras aplicadas na membrana, para cada talhão amostrado. Efetuou-se análise descritiva e comparativa das incidências de colmos infectados (soro-positivos para presença de $L x x$ ) por talhão, por região e por variedade, nos dois anos de levantamento (2003 e 2004).

\section{RESULTADOS E DISCUSSÃO}

No ano de 2003, verificou-se que $65,62 \%$ dos talhões amostrados, correspondentes a 213,53 ha em áreas de multiplicação, estavam contaminados pela bactéria $L$. xyli subsp. xyli ( $L x x)$ (Tabela 1). A bactéria foi detectada em todas as regiões amostradas do Norte do Espírito Santo, Oeste de Minas Gerais e Sul da Bahia. O raquitismo foi diagnosticado tanto em áreas de multiplicação de primeiro corte (cana-planta) quanto em áreas de segundo a sexto corte (socarias). Cerca de $46,87 \%$ dos talhões amostrados foram de cana de primeiro corte (cana-planta). Em cana-planta, a incidência média de raquitismo variou de zero a $34,2 \%$, sendo a maior incidência média observada na variedade SP 791011 na região de Serra dos Aimorés-MG. O talhão com a maior incidência da doença em 2003 (42,85\%) foi em cana de segundo corte (primeira soca) da variedade RB 855035, na região de Linhares-ES. Ainda, em 2003, a incidência média geral de colmos infectados foi maior nos talhões com maior número de cortes, como esperado, devido à natureza poliética do raquitismo da soqueira e a ampla disseminação do patógeno na colheita $(7,8)$. Nos talhões de primeiro corte a incidência média de raquitismo foi de $4,8 \%$ e nos talhões de até quarto corte esta foi de $10,3 \%$, em média. Resultados semelhantes foram observados em levantamento feito por Baudin \& Chatenet (1) em Haute-Volta - França. Dois únicos talhões amostrados de sexto corte (quinta soca) neste estudo apresentaram incidência média de $9,52 \%$ (Figura 1A).

No ano de 2004, constatou-se que 70,45\% dos talhões amostrados, correspondentes a 172 ha, encontravam-se contaminados. Em 2004, observou-se maior incidência média de colmos infectados (18\%) em cana-planta (primeiro corte), indicando que o material propagativo utilizado na renovação dos talhões amostrados estava altamente contaminado, tendo sido provavelmente obtido de campos comerciais com alta incidência de raquitismo. Embora este resultado não era esperado, vez que a doença tende a se agravar com o número de cortes, em 2004, a maioria (54\%) das amostras analisadas (24 talhões dentre 44 amostrados) foram provenientes de talhões de primeiro corte e foi amostrado um maior número de variedades do que em 2003. Portanto, assim como as variedades não foram as mesmas, a origem das mudas em 2004 foi diversa daquelas dos talhões amostrados no ano anterior (dados não apresentados). Em 2004, em cana-planta, a incidência da doença variou de zero a 59,52\% (Tabela 2). A maior incidência ocorreu em talhão em cana-planta da variedade RB 855113. Com relação aos talhões de $2^{\circ}$ a $4^{\circ}$ corte, observou-se um aumento gradativo da incidência média de colmos infectados por idade da cultura (número de cortes), de 6,3 para $13,5 \%$, respectivamente, corroborando com os resultados de 2003.

Embora haja alguma diferença quanto às condições de plantio e quanto ao regime hídrico dentre as regiões amostradas, com base neste levantamento não foi possível comparar as regiões quanto à favorabilidade ao raquitismo, uma vez que o número de amostras por região foi desigual bem como as variedades amostradas em cada região não foram as mesmas, nos dois anos estudados. Há, ainda, diferenças entre talhões de uma mesma variedade quanto à origem das mudas e condições hídricas do solo, resultando em valores médios de incidência de raquitismo discrepantes, de um talhão para outro, de uma região para outra e de um ano para outro, como já comentado (Tabelas 1 e 2). Valores médios de incidência acima de $20 \%$ de colmos infectados por $L x x$ foram observados em praticamente todas as principais regiões amostradas, à exceção de Mucuri, no sul do Estado da Bahia (Figura 1B). O reduzido número de amostras provenientes deste e de outros municípios menos abrangidos por este levantamento, coloca em dúvida uma possível afirmativa quanto a menor prevalência do raquitismo ou quanto à menor favorabilidade ao raquitismo nos municípios e regiões estudadas.

Considerando os dois anos deste levantamento, as variedades com maior número de talhões analisados com suas respectivas incidências de raquitismo foram RB 72454 (4,1\%), SP 801842 (11,7\%), SP 711406 (3,6\%), SP 791011 (13,7\%), RB 855536 (11,2\%) e RB 855113 (12,5\%) (Tabelas 1 e 2, Figura 1C). As variedades que tiveram maior número de talhões amostrados no ano de 2003 foram SP 791011 (IC=11,6\%), SP 801842 (IC=11,54\%), RB 72454 (IC=3,5\%), RB 835486 (IC=6\%) e SP 711406 (IC=2,41\%), as quais são as mais plantadas nas regiões de abrangência deste levantamento. No ano de 2004, as variedades mais analisadas e as respectivas incidências de raquitismo foram RB 72454 (IC=5,5\%), SP 801842 (IC=13,49\%), SP 813250 (IC=4\%), SP 791011 (IC=15,87\%), RB 855536 (IC=16,66\%), RB $855538(\mathrm{IC}=21,42 \%)$ e RB 867515 (IC=8,87\%).

A comparação estatística entre variedades quanto à incidência da doença neste levantamento foi impedida pelo número irregular de talhões amostrados por variedade, pela origem diversa ou desconhecida das mudas bem como devido ao número reduzido de amostras e talhões amostrados em cana-planta para grande parte das variedades estudadas. Todavia, alta incidência de colmos soro-positivos para a presença de $L x x$ indica suscetibilidade varietal, quando não se faz controle da doença por meio da termoterapia dos toletes em viveiros (6). Ademais, a técnica sorológica utilizada só detecta a bactéria sob níveis de colonização elevados, no final da safra, quando a densidade de talos bacterianos supera $2.10^{6}$ u.f.c. $/ \mathrm{mL}(3,9$ e 10). As variedades que apresentaram maiores incidências médias de colmos infectados com Lxx nos dois anos de estudo foram: RB 845257, RB 855035 e SP 716959 , com incidências médias de $29,8 \%, 21,4 \%$ e 21,4\%, e máximas em talhões de $33,3 \%, 42,8 \%$ e 30,9\%, respectivamente (Tabelas 1 e 2, Figura 1E). Dentre as variedades que apresentaram pelo menos um talhão com incidência superior a 40\% estão: RB 855113, RB 855035, RB 855536 e SP 832847 (Tabelas 1 e 2 e Figura 1E). Além destas, as variedades RB 835486, SP 791011, RB 867515, SP 832847, SP 903414, RB 92579, SP 801842, SP 716959, RB 84557 e SP 87-396 apresentaram um ou mais talhões com valores de incidência superiores a 20\%. Ros (20), utilizando o método sorológico de TBIA (Tissue Blot Enzime Immunoassay) para determinar a percentagem de feixes vasculares colonizados por $L x x$, classificou as variedades SP 832847 , SP 791011 e SP 832847 como suscetíveis e as variedades RB 855113, RB 867515, SP 801842 e SP 801816 com resistência intermediária ao raquitismo, em condições de casa-de-vegetação, comparando parcelas com mudas tratadas e não-inoculadas com mudas tratadas e inoculadas. Gagliard et al. (13), utilizaram o método de TBIA para estimar a severidade (proporção de vasos colonizados) do raquitismo em experimento de campo ao longo de três ciclos de produção, entre os anos de 2004 e 2007, no estado de São Paulo. Os autores compararam variedades mais plantadas naquele estado quanto ao número de vasos 
$\mathbf{A}$
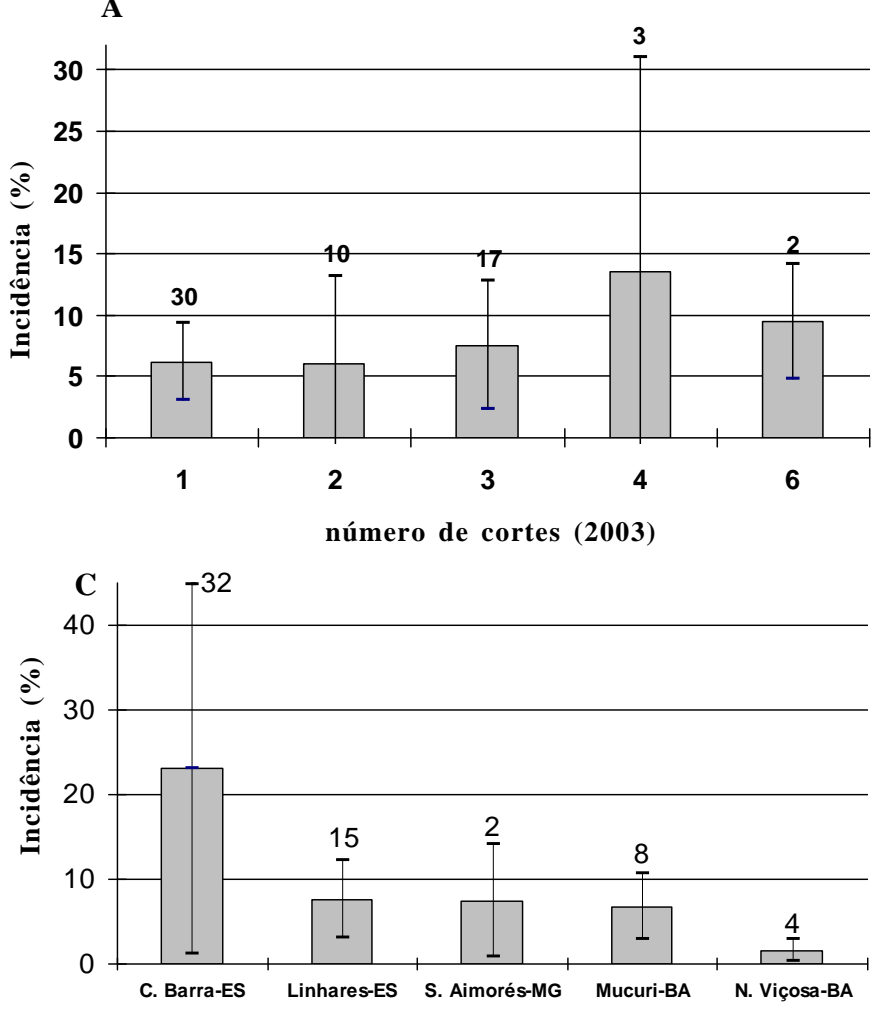

Municípios ou regiões amostradas (2003)
B
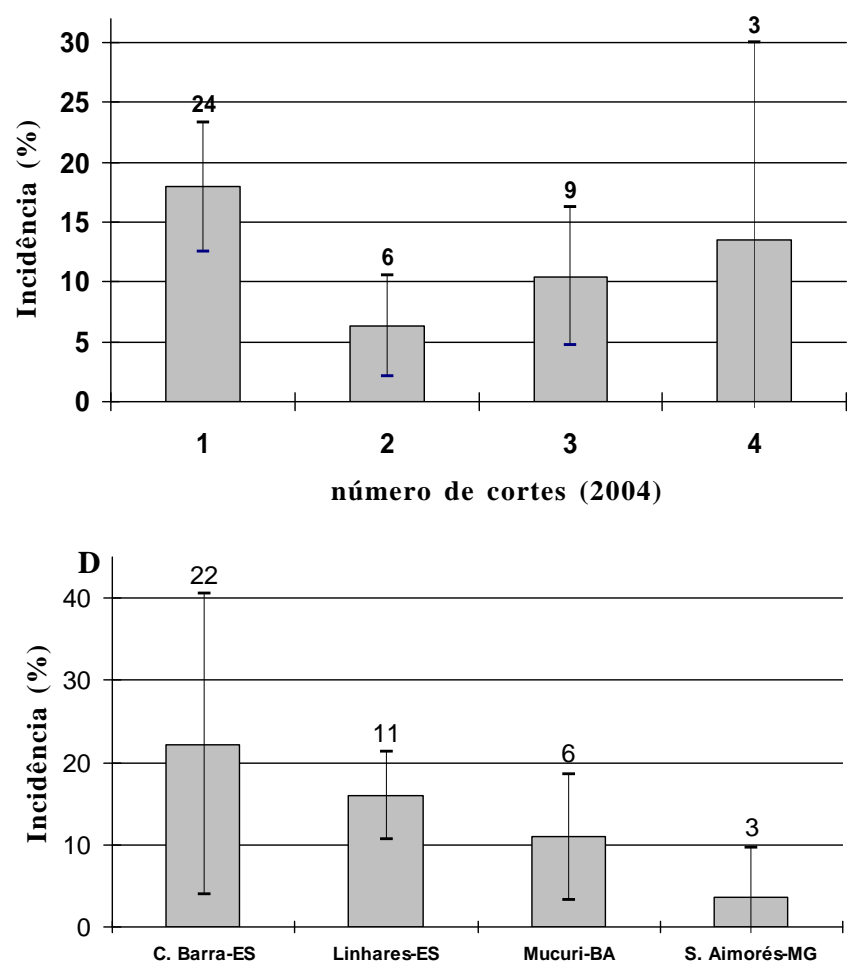

Municípios ou regiões amostradas (2004)

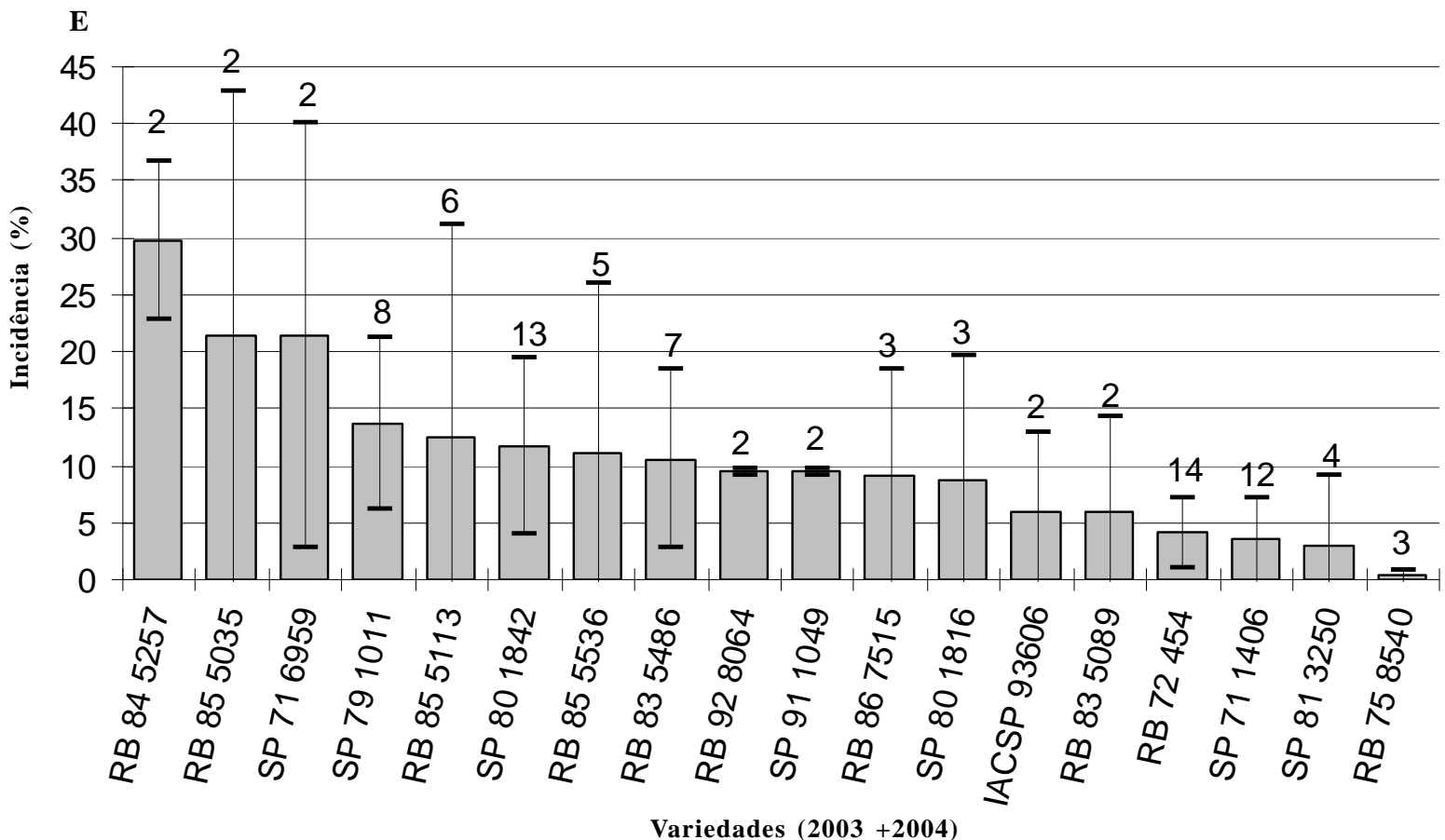

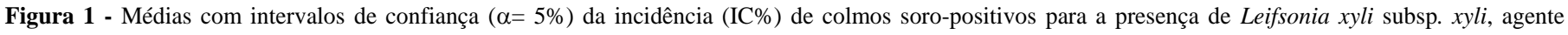
causal do raquitismo da soqueira da cana-de-açucar, obtidas em levantamento em áreas de multiplicação das regiões canavieiras do norte capixaba, oeste mineiro e sul da Bahia. Detecção do patógeno feita pela técnica sorológica Dot Blot-EIA (Carneiro et al., 2004).

A e B - Médias da incidência por número de cortes $\left(1^{\circ}\right.$ corte $=$ cana-planta e de $2^{\circ}$ a $6^{\circ}$. cortes $=$ socas de 1 a 5$)$, nos anos de 2003 e 2004 , respectivamente. C e D - Médias de incidência por região amostrada, nos anos de 2003 e 2004, respectivamente E - Médias de IC nas principais variedades cultivadas nas regiões estudadas. (dados conjuntos de 2003 e 2004). Os números sobre as colunas referem-se ao número de talhões analisados por categoria (corte, região

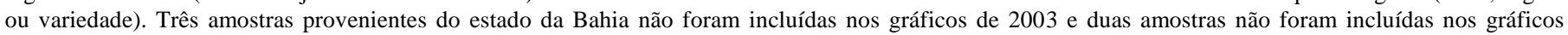
de 2004, por ter sido amostrado um único talhão nestas localidades. 
colonizados e quanto à produtividade em parcelas tratadas (nãoinoculadas) com parcelas tratadas e inoculadas com diferentes densidades de inóculo, obtido a partir de cultura pura. Comportaramse como suscetíveis ao raquitismo as variedades RB 72454, RB 835486, RB 867515, RB 925211e RB 955268, além da variedade padrão suscetível CP 49260. Ainda, as variedades RB 855156, RB 925345 e RB 928064 foram consideradas com resistência intermediária e as cultivares RB 855453 e RB 855536 como tolerantes (13), corroborando os resultados deste levantamento para a maioria dos cultivares em comum, exceto RB 72454 (a diante).

Já, em Conceição da Barra-ES, em 2005, Lima (18) amostrou áreas comerciais contaminadas e pré-implantadas com mudas contaminadas, conforme dados obtidos deste levantamento. Utilizando Dot BlotEIA como método diagnóstico do raquitismo, a autora observou níveis elevados de incidência, entre 40 e $60 \%$ de colmos soro-positivos, para todas as variedades testadas: RB 911049, RB 92579, RB 855453, RB 858927, RB 835486, RB 931530, RB 855113, RB 918639, RB 72454, RB 855511, RB 858539, RB 845210, RB 867515, RB 93509, RB 872552, SP 711406, SP 801816, SP 801842, SP 813250 e SP 832847. No início de 2006 (em cana-planta) e em dezembro de 2007 (segunda soca), a incidência do raquitismo determinada por Dot Blot conciliada as avaliações das características agronômicas e produtividade entre parcelas implantadas com mudas contaminadas, tratadas e não-tratadas por termoterapia, possibilitou Lima (18) considerar as variedades RB 867515, RB 92579, RB 918639, RB 858539, RB 93509, RB 835486, RB 855511, RB 855113 e SP 81-3250 como tolerantes ou pouco tolerantes ao raquitismo, enquanto que as demais variedades foram consideradas intolerantes. Ademais, a autora não observou correlação entre incidência da doença por Dot Blot e produtividade e atribuiu a ampla suscetibilidade varietal, bem como a baixa produtividade geral ao déficit hídrico extremo observado na região de Conceição da Barra em 2007 (déficit hídrico de 546 mm) (18).

Considerando-se o padrão de colonização e o efeito fisiológico deletério à funcionalidade vascular, a resistência ao raquitismo tem sido mais relacionada com a severidade, expressa pelo percentual de vasos colonizados por meio da técnica sorológica de TBIA $(13,15$, 20). Todavia, mesmo utilizando a percentagem de vasos colonizados como medida de severidade e como critério classificatório da resistência varietal, a vasta maioria dos cultivares comerciais mais plantadas em São Paulo é suscetível ao raquitismo $(13,20)$. Isto ocorreu quando as mudas foram inoculadas com caldo contaminado e o experimento foi conduzido em casa-de-vegetação (20) e quando as mudas foram inoculadas a partir de inóculo preparado com cultura-pura de $L x x$ e o experimento foi conduzido no campo (13).

Alguma divergência nos resultados deste estudo em relação aos resultados de Ros (20), Gagliard et al.(13) e Lima (18), quanto à classificação da resistência varietal ao raquitismo pode ser explicada: (i) pelo fato da densidade de talos bacterianos aumentar a cada ciclo no campo $(7,8)$ e as mudas neste levantamento terem sido originadas de talhões comerciais, com altos níveis de contaminação; (ii) pela variação das condições ambientais e experimentais, especialmente com respeito a ocorrência de déficit hídrico; (iii) pela diferença na idade das plantas amostradas; (iv) pelo método de detecção do patógeno e consequentemente pelo critério empregado na avaliação da resistência (15). Neste estudo, mesmo para algumas variedades amostradas em um ou poucos talhões (em média 2 por variedades), nível de incidência acima de $20 \%$ de colmos infectados em "cana-planta" foi considerado indicativo de alta suscetibilidade varietal ao raquitismo. Nada se pode afirmar, entretanto quanto à tolerância à doença, pois dados comparativos de produção entre parcelas plantadas com mudas sadias ou tratadas termicamente e parcelas doentes não foram avaliados neste levantamento.

Ros (20) classificou as variedades SP 801842 e SP 813250 com resistência intermediária. Neste levantamento, entretanto, a variedade SP 801842 apresentou talhões com níveis elevados de incidência, demonstrando suscetibilidade em condições de campo. Já, as variedades SP813250, em quatro talhões amostrados, e RB 758540, em três talhões amostrados, apresentaram em geral baixa incidência de colmos infectados por $L x x$.

A equipe de Fitopatologia da Estação Experimental de cana-deaçúcar do Carpina (EECAC) detectou na variedade SP 791011 alta incidência média de raquitismo no Estado de Pernambuco (18\%) e no Estado do Rio Grande do Norte (11\%) (5). Neste levantamento, em 2003, detectou-se até $34 \%$ de incidência de colmos soro-positivos para presença de $L x x$ na variedade SP 791011, em cana-planta, na região de Serra dos Aimorés-MG (Tabela 1). Ros (20) também considerou esta variedade suscetível ao RSD. Levando-se em consideração que tanto a densidade populacional $(9,10,15)$ quanto à disseminação do RSD no campo $(6,7,8)$ bem como a percentagem de vasos colonizados (20) apresentam correlação direta com suscetibilidade, pode-se considerar que a variedade SP 791011 é muito suscetível ao raquitismo.

As variedades RB 72454, SP 711406 e SP 813250 tiveram número significativo de talhões amostrados nos dois anos de levantamento e, na maioria das vezes, apresentaram incidências inferiores a $10 \%$ de colmos infectados por $L x x$, indicando níveis intermediários de resistência ao raquitismo (Tabelas 1 e 2, Figura 1E). Somente em dois talhões da SP 711406 se observou incidências de colmos infectados acima de 10\%, sendo um em 2003 (IC=19,04\%) e outro em 2004 ( $\mathrm{IC}=14,28 \%$ ). Sanguino (22), avaliando a reação de variedades de canade-açúcar em condições de campo, por três cortes no Estado de São Paulo, observou que a variedade SP 711406 apresentou altas taxas de infecção, corroborando os resultados deste levantamento e de Lima (18). Porém, a variedade SP 711406 é considerada tolerante à presença da bactéria, apresentando geralmente altas produtividades (22). Gagliard et al. (13) obtiveram resultados comparáveis com os do presente estudo para a variedade RB 72454, que é amplamente cultivada no Brasil e nas regiões estudadas, sendo por estes autores considerada como suscetível ao raquitismo. Neste estudo, os níveis de incidência na RB 72454 foram baixos, em geral, e, portanto, a variedade foi classificada com resistência intermediária nas regiões e condições abrangidas por este levantamento.

A variedade RB 765418 é considerada resistente ao raquitismo no Estado de São Paulo (23), o que se confirmou pelos resultados deste levantamento, pois a mesma variedade apresentou incidência baixa de colmos infectados por $\operatorname{Lxx}(7,14 \%)$, mesmo em cana de quinta-soca (sexto corte), na região de Linhares-ES, em 2003 (Tabela 1). Estes resultados, indicam que o levantamento da incidência do raquitismo ao longo das socarias em áreas de produção, embora dispendioso, pode fornecer indicações regionais dos níveis de resistência/ suscetibilidade a esta doença. Idealmente, no entanto, os dados de incidência devem ser confrontados com as variações climáticas e especialmente com o déficit hídrico, além dos dados de produtividade (18).

Algumas variedades apresentaram níveis nulos ou inferiores a 5\% de incidência de colmos infectados em cana-planta e tiveram apenas um talhão analisado por variedade neste levantamento: RB 835054, RB 845210, RB 855453, RB 865230 e SP 801816. A análise da incidência do raquitismo em um único talhão por variedade, principalmente em cana-planta, não assegura resistência muito menos 
imunidade ao raquitismo. Para Gagliard et al (13), a variedade RB 855453 foi tolerante ao raquitismo, pois apresentou baixa redução $(1,93 \%)$ no peso das parcelas tratadas em relação às parcelas inoculadas. Para Ros (20), as variedades RB 835054 e SP 801816 apresentam resistência intermediária e a RB 845210 é susceptível, pois apresentou elevada percentagem de vasos colonizados em casa-de-vegetação.

A avaliação da resistência/tolerância ao raquitismo deve considerar o aumento da incidência com os cortes na socaria (7), bem como incluir avaliações de produtividade entre parcelas sadias ou provenientes de mudas tratadas e parcelas doentes $(9,13,18,20)$. Priorizou-se, neste estudo, o levantamento em áreas de multiplicação de primeiros cortes, visando-se estabelecer uma relação da incidência da doença com a sanidade das mudas utilizadas na região. Todavia, a ocorrência de alta incidência da doença em cana-planta, para maioria das variedades mais plantadas, coloca em evidência a suscetibilidade varietal, visto que nas regiões deste levantamento muitas áreas de multiplicação foram estabelecidas com mudas não-tratadas e provenientes de áreas de produção. Até o momento, não são conhecidas variedades comerciais de cana-de-açucar com resistência total ou que sejam imunes ao raquitismo $(9,10,13,15,16,18$ e 20). Em geral, a resistência ao raquitismo e a outras doenças na cultura da cana-de-açucar é do tipo parcial e supostamente tem herança quantitativa (13), cuja expressão dos genes de resistência pode sofrer forte interferência do ambiente. Ademais, as condições edafoclimáticas locais e o manejo da cultura podem interferir na interação planta-patógeno, reduzindo a resistência e a tolerância de algumas variedades ao raquitismo, conforme constatado por Lima (18). Neste trabalho, a maioria das variedades estudadas, mesmo algumas previamente consideradas com resistência intermediária apresentaram níveis elevados de incidência de colmos infectados por $L x x$, já nos primeiros cortes. As poucas variedades que apresentaram incidência nula foram pouco amostradas, indicando que para caracterização destas, novos estudos e levantamentos regionais da incidência do raquitismo devem ser conduzidos em áreas de multiplicação, ou mesmo nas socarias em áreas comerciais.

Com o presente levantamento foi possível fazer um diagnóstico regional quanto à prevalência do raquitismo da soqueira da cana-deaçúcar em áreas de multiplicação em municípios do Espírito Santo, oeste de Minas Gerais e sul da Bahia. O conhecimento do nível de resistência ou tolerância das variedades mais cultivadas nestas regiões deve orientar o manejo varietal e cultural. No segundo caso, deve-se concentrar a renovação de canaviais e o tratamento de mudas por termoterapia nas variedades suscetíveis e intolerantes a doença. As elevadas incidências de colmos infectados pela bactéria $L x x$, verificados nos dois anos de amostragem em áreas de multiplicação de cana-deaçúcar, confirmam que este patógeno encontra-se amplamente disseminado nas regiões estudadas. Apesar de não haver registros antecedentes de levantamento da incidência da bactéria $L x x$ nas regiões abrangidas neste estudo, os resultados não surpreendem, devido ao desuso do tratamento térmico para produção de mudas sadias, largamente difundido na década de 80 (21). Além disso, salienta-se a não implementação de viveiros e o amplo intercâmbio de materiais propagativos no Brasil, o que contribui para o estabelecimento e disseminação da doença nas regiões produtoras. As empresas canavieiras da região importam frequentemente mudas dos estados do Rio de Janeiro, São Paulo e Minas Gerais. Já, no Estado do Rio de Janeiro, as mudas são predominantemente da região canavieira de Campos dos Goytacazes, onde a bactéria foi primeiramente relatada no Brasil, há 54 anos passados (24).

A sensibilidade do método diagnóstico empregado é baixa, de $2.10^{6}$ bactérias/mL (3), e pode ainda ser reduzida pelo efeito da diluição da bactéria na seiva das plantas, em decorrência do crescimento vegetativo. Como no ano de 2004 as incidências de colmos infectados foram em média superiores a 2003, apesar do regime hídrico em 2004 ter favorecido o crescimento da cultura (dados não apresentados), aventase que as áreas de multiplicação de onde se obtiveram as mudas para o plantio em 2004 detinham níveis de contaminação mais elevados do que as de 2003. De todo modo, a prevalência e a incidência da doença foram altas, nos dois anos deste levantamento, o que evidenciou a falta de controle do raquitismo-da-soqueira bem como má condição sanitária das mudas. São raras as empresas que fazem práticas de controle do raquitismo em seus viveiros e a maior parte das mudas das regiões estudadas são provenientes de plantios comerciais ou áreas de multiplicação, muitas das quais, como constatado neste levantamento, apresentam alta incidência de raquitismo, mesmo em cana de primeiro corte (mínimo de $1,19 \%$ e máximo de $59,52 \%$, considerando os dois anos do levantamento). Como canaviais comerciais estão sendo reformados ou implantados com elevada carga de inóculo, perdas significativas de produtividade agravadas pelo raquitismo poderão advir em anos de estiagens prolongadas.

Conclui-se que o raquitismo da soqueira encontra-se largamente disseminado pelas regiões produtoras de cana-de-açúcar do norte capixaba, oeste mineiro e sul da Bahia, o que, provavelmente, contribui de maneira negativa na produtividade da cultura. Estudos adicionais devem ser conduzidos, no sentido de se caracterizar melhor as variedades regionais mais promissoras, avaliando-se a incidência do raquitismo nas socarias e, também, em experimentos especialmente delineados, com parcelas implantadas com mudas tratadas e nãotratadas termicamente, com respectivas avaliações de produtividade e da percentagem de vasos colonizados. Ademais, a falta de variedades efetivamente resistentes à infecção e à colonização por $L x x$, especialmente sob condição de déficit hídrico, reforça a necessidade dos programas de melhoramento buscarem novas combinações híbridas e variedades mais adaptadas às condições edafoclimáticas regionais.

\section{AGRADECIMENTOS}

À Universidade Estadual do Norte Fluminense "Darcy Ribeiro" e ao Programa de Pós-graduação em Produção Vegetal do Centro de Ciências e Tecnologias Agropecuárias da UENF, pelo treinamento ao primeiro autor, bem como a CAPES, pela bolsa de pós-graduação. Ao Campus Dr. Leonel Miranda da UFRRJ por todo apoio logístico e mão-de-obra solícita. As Usinas DASA, LASA, DISA e ALCON pela participação e apoio ao projeto.

\section{REFERÊNCIAS BIBLIOGRÁFICAS}

1. Baudin, P.; Chatenet, M. Présence de la maladie du rabougrissement des repousses de la canne à sucre en Haute-Volta. L'Agronomie Tropicale, Paris, v. 38, n. 3, p. 241-243, 1983.

2. Carneiro, J.B.; Ponte, E.C.; Silveira, S.F.; Olivares, F.L. Método de extração de seiva do xilema de cana-de-açúcar e detecção sorológica por dot blot de Leifsonia xyli subsp. xyli. In: XXXVI Congresso Brasileiro de Fitopatologia - Manejo Integrado de Doenças de Plantas, 2003, Uberlância-MG. Fitopatologia Brasileira, Brasília, v.28, supl., p.244-244, 2003. (abstract). 1 CD-ROM (abstract).

3. Carneiro, J.B.; Silveira, S.F.; Souza-Filho, G.A.; Olivares, F.L.; Giglioti, E.A. Especificidade de antissoro policlonal à Leifsonia xyli subsp. xyli. Fitopatologia Brasileira, Fortaleza, v.29, n.6, p.614-619, 2004. 
4. Chagas, P.R.R. \& Matsuoka, S. Medidas de controle do raquitismo da soqueira. Brasil Açucareiro, Rio de Janeiro, v.106, n.1, p.4044, 1988 .

5. Chaves, A.; Pedrosa, E.M.R.; Cavalcante, J.F.D.; Araújo, C.F.S.; Ferreira, G.E. Comportamento de variedades comerciais de canade-açúcar em relação ao raquitismo da soqueira (Leifsonia xyli subsp. $x y l i$ ) na região nordeste do Brasil - avaliações em canaplanta. In: Congresso Nacional da STAB, 8., 2002. Pernambuco. Anais. Piracicaba: STAB, 2002. p. 27-34.

6. Comstock, J.C., Perdomo, R., Powell, G.; Zhongkang, W. Ratoon stunting disease in Florida sugarcane fields: relationship between disease incidence and cultivar resistance. Journal American Society Sugarcane Technologists, Baton Rouge, v.17, p.95101, 1997.

7. Comstock, J.C., Shine, J.M., Davis, M. J. \& Dean, J. L. Relationship between resistance to Clavibacter xyli subsp. xyli colonization in sugarcane and spread of ratoon stunting disease in the field. Plant Disease, St. Paul, v.80, n.6, p.704-708, 1996.

8. Damann, K. E., Jr. Effect of sugarcane cultivar susceptibility on spread of ratoon stunting disease by the mechanical harvester. Plant Disease, St Paul, v.76, p.1148-1149, 1992.

9. Davis, M.J. Distribution of Clavibacter xyli subsp. xyli in stalks of sugarcane cultivars differing in resistance to ratoon stunting disease. Plant Disease, St. Paul, v.72, p.443-448, 1988.

10. Davis, M.J.; Dean, J. L.; Harisson, N. A. Quantitative variability of Clavibacter xyli subsp. xyli populations in sugarcane cultivars differing in resistance to ratoon stunting disease. Phytopathology, St. Paul, v. 78, p. 462-468, 1988.

11. Davis, M.J., Gillaspie, A.G., Vidaver, A.K., Harris, R.W. Clavibacter, a new genus containing some phytopathogenic coryneform bacteria Clavibacter xyli subsp. xyli sp.nov., subsp. nov. and Clavibacter xyli subsp. cynodontis subsp. nov., pathogens that cause ratoon stunting disease of sugarcane and Bermudagrass stunting disease. International Journal of Systematic Bacteriology, Washington, v.34, n.2, p.107-117. 1984.

12. Evtushenko, L.I.; Dorofeeva, L.V.; Subbotin, S.A.; Cole, J. R.; Tiedje, J.M. Leifsonia poae. gen. nov., sp. nov., isolated from nematode galls on Poa annua, and reclassification of "Corynebacteriujm aquaticum" Leifson 1962 as Leifsonia aquatica (ex Leifson 1962) gen.nov., nom. rev. comb. nov. and Clavibacter xyli Davis et al. 1984 with two subspecies as Leifsonia xyli (Davis, et al 1984) gen. nov. comb. nov. International Journal of Systematic and Evolutionary Microbiology, Washington, v.5, p.371-380, 2000 .

13. Gagliard, P.R.; Camargo, L.E.A. Resistência de variedades comerciais de cana-de-açucar ao agente causal do raquitismo-da-soquei- ra. Ciência Rural, Santa Maria, v.39, n.4, p.1222-1226, 2009.

14. Gillaspie, A. G. Ratoon stunting disease of sugarcane serology. Phytopathology, St. Paul, v. 68, p. 529-532, 1978.

15. Giglioti, E.A.; Comstock, J.C.; Davis, M.J.; Matsuoka, S.; Tokeshi, H. Aplicação do tissue blot imunoassay e do método de coloração dos vasos do xilema por transpiração para avaliação da colonização de colmos de cana-de-açúcar por Clavibacter xyli subsp. xyli e de seu efeito na funcionalidade do xilema. Summa Phytopathologica, Piracicaba, v.25, n.2, p.125-123, 1999.

16. Harrison, N.A.; Davis, M.J. Infectivity titrations of Clavibacter xyli subsp. xyli and sugarcane cultivars differing in susceptibility to ratoon stunting disease. Plant Disease, St. Paul, v.70, n.6, p.556-558, 1986 .

17. Leaman, T.M., Teakle, D.S., Croft, B.J. Comparison of serological diagnostic tests for the detection of Clavibacter xyli susbp $x y l i$, the causal bacterium of ratoon stunting disease in sugarcane. In: Australian Society of Sugar Cane Technologists, v.13, 1991, Auchenflower. Proceedings... p.88-94.

18. Lima, R.M.P. Caracterização de variedades de cana-de-açúcar quanto a resistência e tolerância ao raquitismo-dasoqueira. 2008. 59f. Tese (Mestrado em Produção Vegetal) Universidade Estadual do Norte Fluminense Darcy Ribeiro, Campos dos Goytacazes.

19. Pan, Y.B., Grisham, M.P., Burner, D.M.A. Polymerase chain reaction protocol for the detection of Clavibacter xyli subsp. xyli the causal bacterium of sugarcane ratoon stunting disease. Plant Disease, St. Paul, v.82, n.3, p.285-290, 1998.

20. Ros, P.B. Avaliação da resistência de variedades de canade-açúcar ao raquitismo da soqueira com base na taxa de colonização dos colmos por Leifsonia xyli subsp. xyli. 2004. 58f. Tese (Mestrado em Ciências) - Escola Superior de Agricultura "Luiz de Queiroz", Universidade de São Paulo, Piracicaba.

21. Ruas, D.G.; Matsuoka, S.; Gheller, A.C.A. Situação do uso do equipamento de tratamento térmico no Centro-Sul na safra 1985/1986. Brasil Açucareiro, Rio de Janeiro, v.105, n.1, p.13-16, 1987.

22. Sanguino, A.; Moraes, V.A.; Filho, O.T.S. Diagnóstico do raquitismo da soqueira em colmos de cana-de-açúcar. In: Seminário de tecnologia agronômica, 2., Anais. Piracicaba: Copersucar, 1984. p. 250-253.

23. Tokeshi, H. Doenças da cana-de-açúcar. In: Kimati, H.; Amorim, L; Bergamin-Filho, A.; Camargo, L.E.A.; Rezende, J.A.M (Ed.). Manual de Fitopatologia: doenças de plantas cultivadas. $3^{\text {rd }}$ ed. São Paulo: Agronômica Ceres, 1997. v.2, cap.19, p. 207-225.

24. Veiga, F. M. Notas sobre o raquitismo das socas em Campos. Brasil Açucareiro, Rio de Janeiro, v.47, n.1, p.81-83, 1956. 